Ann. rheum. Dis. (1969), 28, 270

\title{
BACTERIAL L-FORMS IN THE BLOOD AND JOINT FLUIDS OF ARTHRITIC SUBJECTS
}

\author{
BY \\ PHYLLIS PEASE \\ From the Department of Bacteriology, University of Birmingham
}

The possibility that bacteria in a sub-cellular phase (including L-forms, mycoplasmata, and Bedsonia) may be associated with arthritic disease has been much discussed, and it has been suggested (Pease, 1965, 1967a, 1968) that arthritis and other diseases with an autoimmune element could be initiated by a breakdown of immunological tolerance in respect of a widespread and normally tolerated parasite. The Gram-positive bacteria, often classified as Listeria, that are frequent blood-parasites of man and other vertebrates, could fill this role, as they are found to occur in much greater numbers in arthritic subjects than in healthy persons (Alexander-Jackson, 1954; Fleisher, 1952; Pease, 1967a). Although the classification and identification of micro-organisms of this type are not easy, it is my opinion that the "diphtheroid" bacilli, isolated by Duthie, Stewart, Alexander, and Dayhoff (1967) from arthritic joints, are one of the phases of these bacteria, and that this is probably true of various other isolates.

Bacterial L-forms and spheroplasts are not easy to detect by classical bacteriological methods, and may be missed completely (indeed it is apparent that they frequently have been missed by investigators who have found arthritic blood and joint fluids to be sterile). At the same time, since they may take a very long time to revert to the bacillary phase, on isolation, and may never do so, they are liable to be confused with mycoplasmata, which they closely resemble.

Detection of Listeria L-forms, either directly in the blood and joint fluids, or in primary cultures, can best be achieved by electron or phase-contrast microscopy, and one of the objects of this paper is to describe and illustrate the appearances of this little-known microbe, as well as to contribute further evidence of its occurrence in arthritis.

\section{Methods}

62 samples of blood and 75 of joint fluids were taken with sterile precautions from 24 cases of rheumatoid arthritis (diagnosed by clinical findings, $x$ rays, and serological tests), four of osteoarthritis (diagnosed by clinical findings), and twelve of clinical arthritis (otherwise undiagnosed). These were obtained from patients in the St John's and Highfield Hospitals, Droitwich, and the Queen Elizabeth Hospital, Birmingham, by the courtesy of Drs C. F. Hawkins, A. J. Popert, and J. D. Goode. Cultures were made by adding $2 \mathrm{ml}$. serum or joint fluid to $15 \mathrm{ml}$. Brewer's medium in a McCartney screw-capped bottle, and incubating at $37^{\circ} \mathrm{C}$, until slight visible turbidity could be detected with the naked eye, which was usually after 2 to 6 weeks. The growth was concentrated by centrifugation at 2,500 r.p.m., and re-suspended in $1 \mathrm{ml}$. sterile distilled water for examination. For electron microscopy, this suspension was used directly upon the membrane; for phase-contrast microscopy, a few drops were mounted between slide and coverslip and sealed at the edges with beeswax. These were examined with a Wild $\times 50$ phase-contrast lens and condenser. In some cases, the serum or fluid was examined directly, by these means, without prior culturing. Photomicrographs were made on the same apparatus.

\section{Results}

Positive cultures were obtained from all the samples examined, and were all similar. Phasecontrast appearances are illustrated in Figs 1 to 6. The dark, spherical bodies are bacterial spheroplasts, and some of these are clearly seen to be budding. 

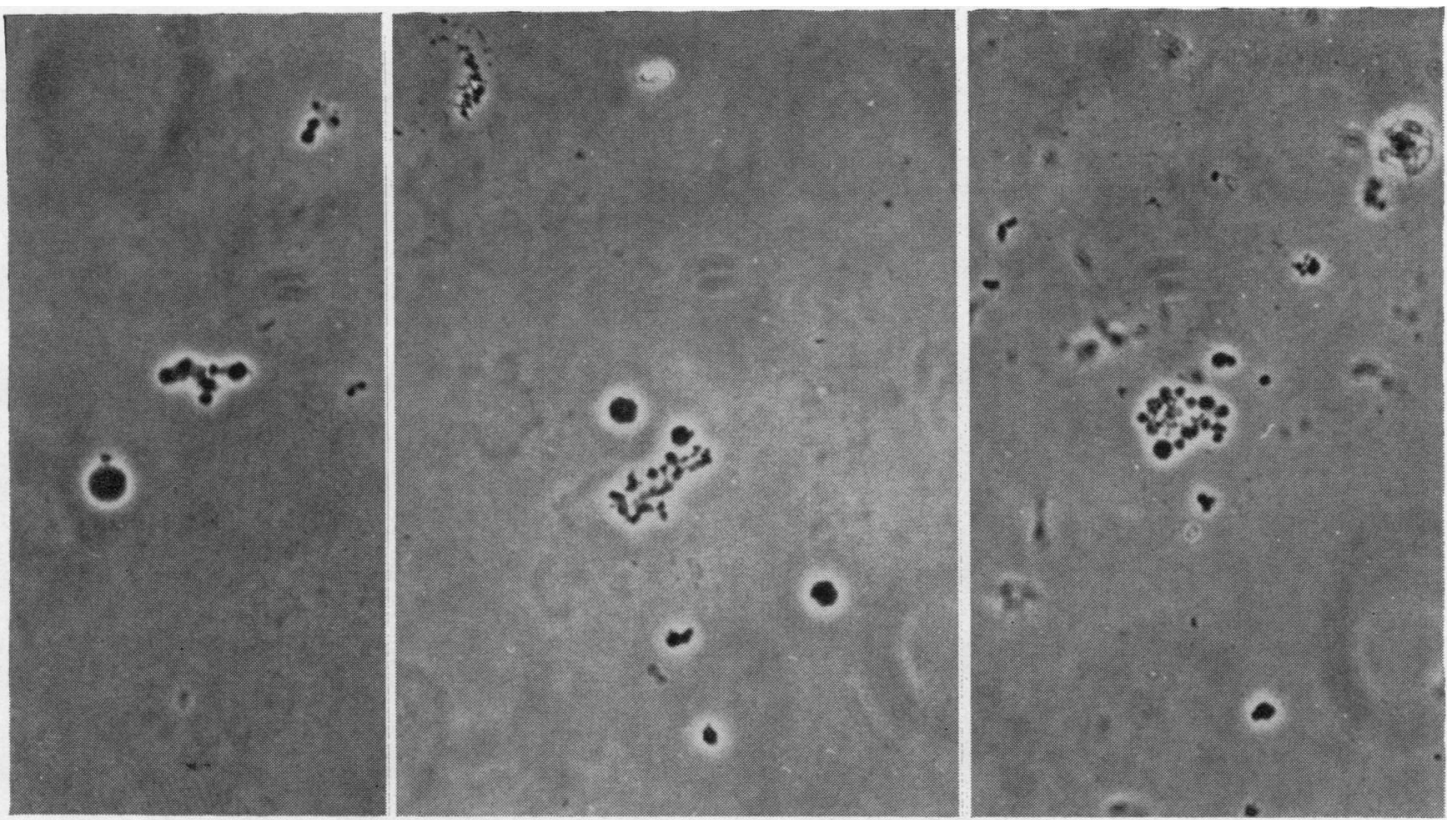

Figs 1, 2, 3.-Groups of large and small bacterial spheroplasts from primary cultures of synovial fluid in Brewer's medium. 6 weeks' incubation. Phase-contrast. $\times 1,250$.
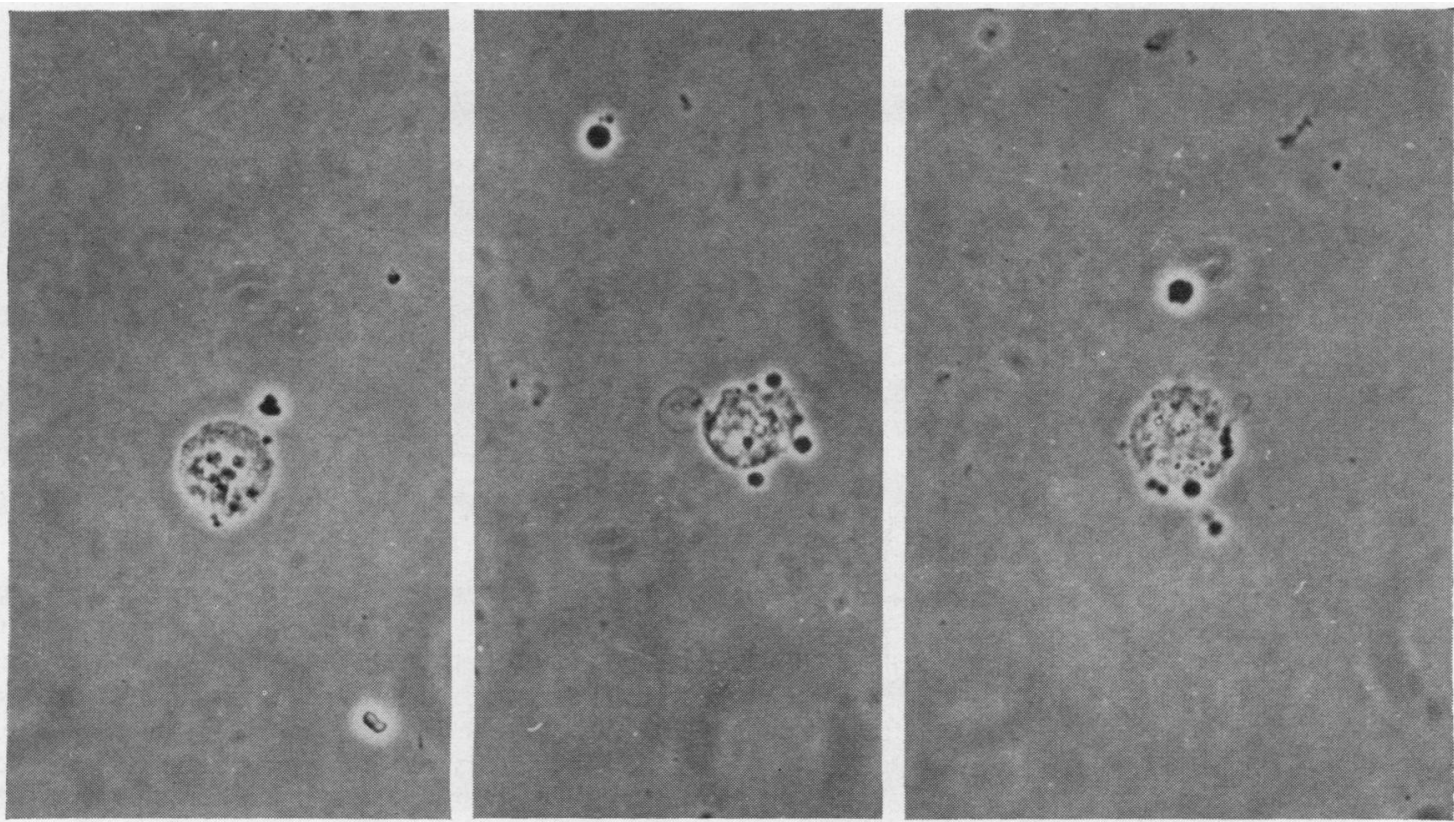

Figs 4, 5, 6.-Spheroplasts and cysts from primary cultures of synovial fluid in Brewer's medium. 6 weeks' incubation. Phase-contrast. $\times 1,250$.

The spheroplasts are often assembled in groups (Figs $1,2,3)$ and are also associated with the cyst-like bodies reported previously from cultures of this type (Pease, 1967a) (Figs 4, 5, 6). 
The appearance of the cysts in the electron microscope is shown in Fig. 7. In a proportion of cultures, the cysts aggregated into relatively large symplasms (Fig. 8), in which suggestions of filamentous structure could be seen by phase-contrast, but not in the electron microscope. These larger symplasms were characteristic of cultures from three cases of rheumatoid arthritis out of the nineteen examined.

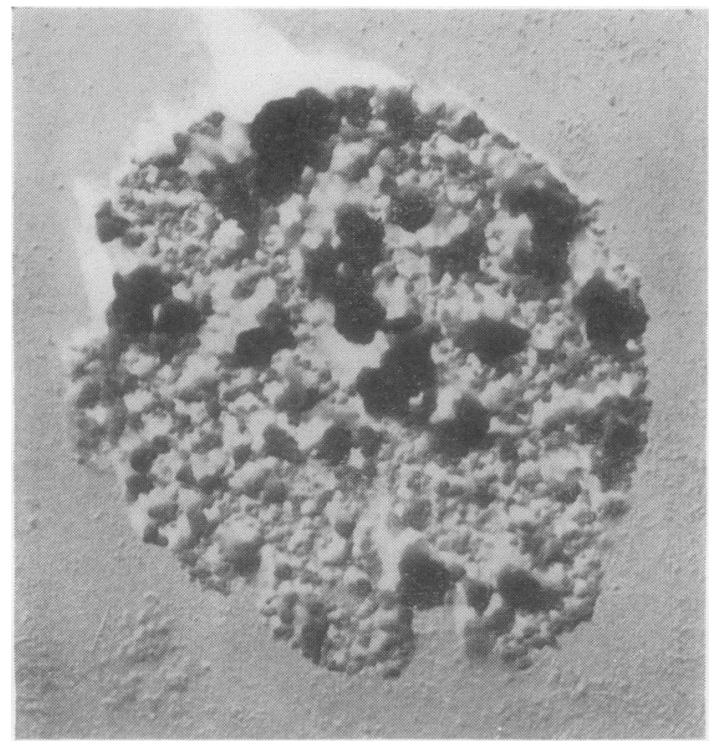

Fig. 7.-Cyst, as in Figs 4, 5, and 6. Electron micrograph, goldpalladium shadowed. $\times 10,000$.

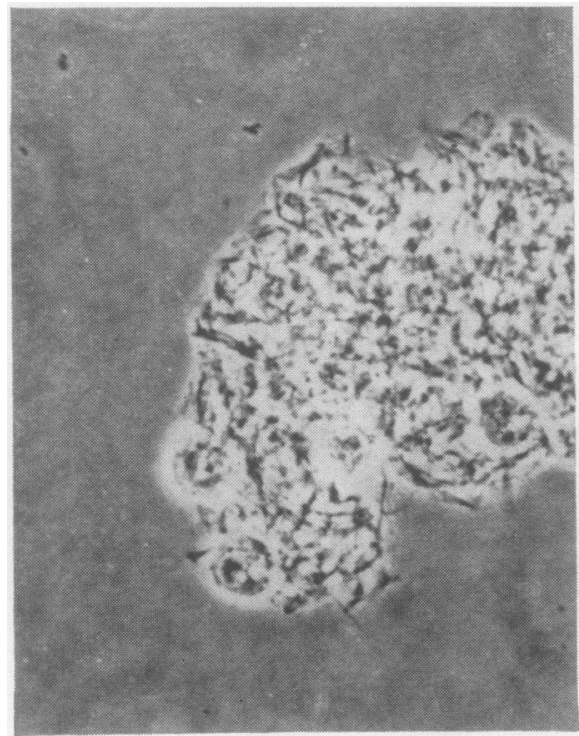

Fig. 8.-Cysts and symplasm with filamentous appearances, from primary culture of synovial fluid in Brewer's medium. 6 weeks incubation. Phase-contrast. $\times 1,250$.
In most cultures there were also to be found other elements associated with bacterial L-phase growth, including occasional "diphtheroid" rods and very small rods and spheres which might have been identified as viruses or Bedsonia. The smaller elements could not be distinguished clearly by visible light, but only in the electron microscope (Fig. 9). However, the spheroplasts and cysts were the characteristic visible elements in all the cultures examined.

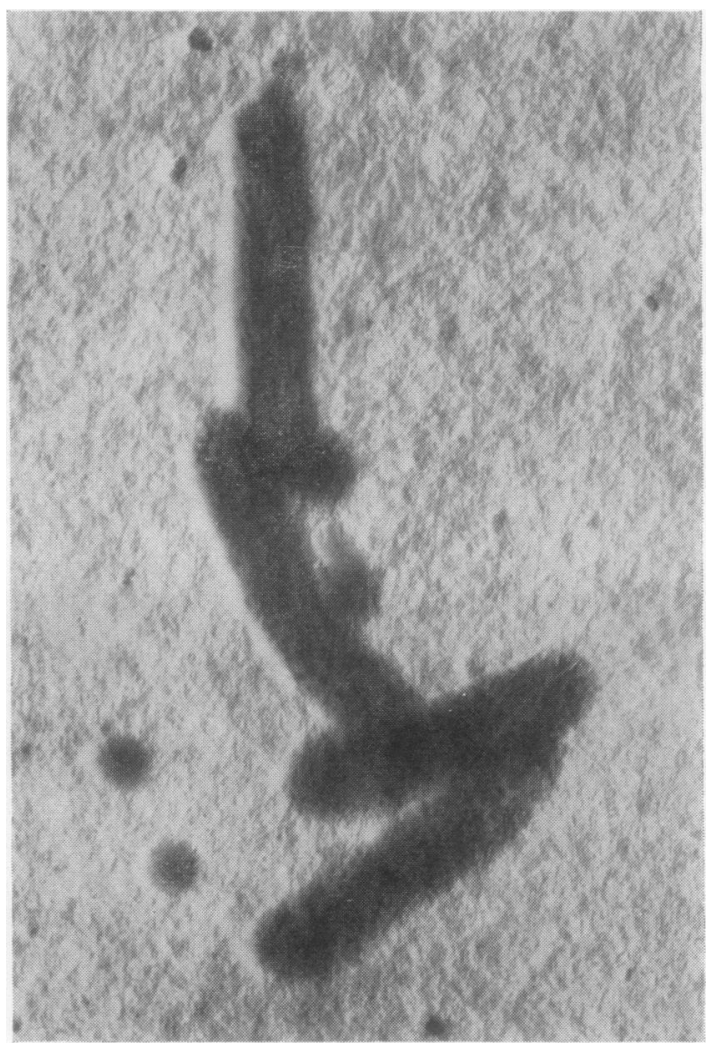

Fig. 9.-Bacterial forms and small spherical bodies, from primary blood-culture in Brewer's medium. 6 weeks' incubation. Electron micrograph, gold-palladium shadowed. $\times 20,000$.

Direct examination was made of centrifuged precipitate from 29 fluids, of which one showed numerous spheroplasts, symplasms, and minute bacterial forms. The appearances in this case (of rheumatoid arthritis) were exactly similar to those found in primary cultures from the remaining cases. This observation serves to check the validity of the cultural procedure.

The process of reversion to the bacterial phase, whereby the organism was diagnosed as a phase of Listeria sp., was variable and rather unpredictable. In most cultures a very small number of recognizable bacteria could be observed, if the cultures were 
carefully examined, after about 2 weeks' incubation. On prolonged incubation, the proportion of bacteria increased until, in about one-quarter of cultures, the bacterial form was predominant. In the remainder, the two phases of growth remained mixed. This supports the findings of Duthie and others (1967), who obtained bacterial cultures in this proportion of cultures after blind subcultures. Comparable results were obtained by Fleisher (1952), who speculated on the existence of an unrecognizable phase.

Subcultures could be made with ease from the bacterial phase, and with some difficulty from the L-phase primary cultures. The types of growth obtainable on subculture were in accordance with the findings of Alexander-Jackson (1954), and are in process of further examination.

\section{Discussion}

The evidence recorded in this paper is presented with a double purpose: first, to provide direct evidence of the association of L-forms of Grampositive bacteria with arthritis, in support of my hypothesis (Pease, 1965) that they may be capable of provoking an autoimmune disturbance; and secondly to illustrate these organisms, as seen by simple and readily repeatable cultural and microscopic methods, appropriate to the handling of this rather difficult biological material. It is my opinion that the divergent results obtained by different workers in this vexed field of study are due mainly to the technical hazards entailed. These L-forms, provisionally identified as related to the genus Listeria, are not only liable to be identified as mycoplasmata, Bedsonia, or corynebacteria; they are even more apt, because of their fragility and very slow growth in culture, to be overlooked entirely, when classical bacteriological methods are employed; since neither a heat-fixed, Gram-stained film, nor a 48-hour culture will regularly give a positive result. Conversely, because of the great morphological variability of this bacterium (Pease, 1967a), such positive cultures as may be obtained are likely to contain a variety of growth phases, some resembling Gram-positive cocci and bacilli, and are accordingly in risk of being discarded as contaminants.

These findings are not unique. It has already been pointed out that they are in complete accord with the cultural observations of Duthie and others (1967), who concentrated on the bacterial phase. All the morphological forms have been described by Alexander-Jackson (1954), who, although concerned mainly with malignant disease, considered that these bacteria (which she illustrated in detail, but did not identify) were associated with arthritis. Roberts (1964) found the L-forms of a Gram-positive bacillus in fowl arthritis. Comparable phasecontrast observations have been published, of material from renal and cardiac disease (Guze, 1968); these are relevant to the argument, because, in terms of my own hypothesis of causation (Pease, $1965,1967 a)$, these conditions are directly comparable with arthritis.

The present findings are also compatible with the numerous descriptions of mycoplasmata and Bedsonia associated with arthritis in man and animals. Quite apart from the separate and distinct problem of whether these micro-organisms can be a cause of arthritis, which may well be true, bacterial L-forms do contain elements, including those illustrated here, that bear a strong resemblance to mycoplasmas and bedsonias in their morphology. In my experience, the L-forms of bacteria of this group are indistinguishable from mycoplasmas, and recent work by Dienes and Bullivant $(1967,1968)$ confirms that this is true of $\mathbf{L}$-forms of many bacterial genera. Nor can complete trust be placed upon serological identification,'sinceit has been shown that numerous antigens are common to mycoplasmas and bacteria (Pease, 1967b). This includes streptococcal antigens; the importance of this phenomenon in rheumatic and rheumatoid disease is discussed elsewhere (Pease, 1968).

Thus, while there is no intention of claiming that these L-forms are the only possible agent concerned in arthritic disease, and my hypothesis does not require that they should be, there is distinct evidence that bacteria of this type are associated with arthritides, not only in man, but in other animals. In particular, swine arthritis, which is very similar to human rheumatoid arthritis (Hollander, 1966), is generally accepted to be associated with Erysipelothrix infection. This bacterium is so similar to Listeria that some authorities doubt whether they should be placed in separate genera (Wilson and Miles, 1964). The rodent arthritis organism Streptobacillus moniliformis is also very similar, and it is worthy of mention that its L-form was for some years classified as a mycoplasma (Klieneberger, 1935).

In conclusion it must be borne in mind that this association of the infective micro-organism with the pathological condition does not satisfy Koch's postulates. Although it is found with regularity in cases of arthritis, it is also widespread among apparently healthy persons (see Pease, 1967a, for a review of the literature). The disease must be 
regarded as a disturbance of immune tolerance, in which this, or any other infective agent, is only one factor.

\section{Summary}

Primary cultures prepared from 81 samples of blood and joint fluid from 29 arthritic subjects were found to contain L-forms of a bacterium resembling Listeria.
I wish to acknowledge the encouragement and assistance of Dr K. A. Bisset, Dr C. F. Hawkins, and Prof. K. W. Walton, the kind assistance of Drs A. J. Popert, J. D. Goode, and D. R. Stanworth, the valuable help of Mr C. C. Newton on the electron microscope, and of Miss Judy Johnston in both technical work and photography. I wish also to thank the Arthritis and Rheumatism Council, who provided the phase-contrast microscope that enabled this demonstration to be made.

\section{REFERENCES}

Alexander-Jackson, E. (1954). Growth, 18, 37 (A specific type of microorganism isolated from animal and human cancer: bacteriology of the organism).

Dienes, L., and Bullivant, S. (1967). Ann. N.Y. Acad. Sci., 143, 719 (Comparison of the morphology of PPLO and L-forms of bacteria with light and electron microscopy).

- (1968). J. Bact., 95, 672 (Morphology and reproductive processes of the L-forms of bacteria. II. Comparative study of $L$-forms and Mycoplasma with the electron microscope).

Duthie, J. J. R., Stewart, S. M., Alexander, W. R. M., and Dayhoff, R. E. (1967). Lancet, 1, 142 (Isolation of diphtheroid organisms from rheumatoid synovial membrane and fluid).

Fleisher, M. S. (1952). Amer. J. med. Sci., 224, 548 (Significance of diphtheroid microorganisms in blood cultures from human beings).

Guze, L. (ed.) (1968). "Symposium: Microbial Protoplasts, Spheroplasts and L-forms", pp. 382-8, 418, 436-8. Williams and Wilkins, Baltimore.

Hollander, J. L. (1966). “Arthritis and Allied Conditions", 7th ed. Lea and Febiger, Philadelphia.

Klieneberger, E. (1935). J. Path. Bact., 40, 93 (The natural occurrence of pleuropneumonia-like organisms in apparent symbiosis with Streptobacillus moniliformis and other bacteria).

Pease, P. E. (1965). "L-forms, episomes and auto-immune disease". Livingstone, Edinburgh.

- (1967a). Nature (Lond.), 215, 936 (Tolerated infection with the sub-bacterial phase of Listeria). (1967b). J.gen. Microbiol., 49, 433 (Antigenic relationships between oral group D streptococci, some Haemophilus species and Mycoplasma hominis).

- (1968). In "Rheumatic Diseases" (Pfizer Medical Monograph 3), ed. J. J. R. Duthie and W. R. M. Alexander, p. 165 . University Press, Edinburgh.

Roberts, D. H. (1964). Res. vet. Sci., 5, 441 (L-phase bacterial forms associated with infectious synovitis in chickens and turkeys).

Wilson, G. S., and Miles, A. A. (1964). "Topley and Wilson's Principles of Bacteriology and Immunity", 5th ed., p. 532. Arnold, London.

Les bactéries à formes $L$ dans le sang et le liquide des articulations des sujets arthritiques

\section{RÉsumé}

Les cultures primaires préparées de 81 échantillons de sang et de liquide des articulations obtenus de 29 sujets arthritiques ont montré les formes $L$ d'un bactérium ressemblant au Listeria.
Bacterias con forma de " $L$ " en la sangre y los fluidos articulares de sujetos artríticos

\section{Summario}

Se descubrió que los cultivos primarios preparados a base de 81 muestras de sangre y fluido articular de 29 sujetos artríticos contenían formas " $L$ " de una bacteria parecida a la Listería. 